\title{
Traditional Architecture as the Medium of Public Ethical Value
}

\author{
Cheng-xia XIONG ${ }^{1, a,{ }^{*}}$ and LIMBAROYATI',b \\ ${ }^{1}$ Room 301, \#103905th Alley, Pudong Southeast Road, \\ Pudong New District, Shanghai City, China. \\ ${ }^{2}$ Budi Mulia Rd Ampera 4 No.4A, Jakarta, Indonesia \\ axiongarticle@126.com, bno_v_lyn@hotmail.com
}

Keywords: Building the image, Ethical symbol, Media narrative, Form the semantic, Space system.

\begin{abstract}
Traditional Chinese architecture in the narrative of a system of more than 3000 years, As the core values of the enlightenment function of social ethics, Traditional architectural externalizing symbol of "state" sensual ethical echo, So that the construction of metaphor in order code and the profane life each other, Traditional architectural form as famous communication home Marshall McLuhan's "human extension", The spread of universal ethics, Traditional architectural symmetry axis ceremony, the adornment of the mythical thinking component, It is traditional Chinese ethics society to describe the core of creation thought three points sequence structure constraint, In the construction of the contemporary social upheaval spreading vision, Recognition of traditional architecture ethics through righteousness obviously has the recasting social ethics of "treatment".
\end{abstract}

When the literature through the historical of the story describes the dissemination of content, the architecture also undeniably uses the metaphorical "events" outside of the narrative function of "visual form, spatial axis, scale facade, decorative component, and cultural semantics". The space in the building that mankind has been carrying since the great tradition already far beyond the "shelter", Its extension becomes a multi-level communication material, such as "etiquette" symbol, body metaphor, ethical education and so on. As McLuhan says "medium is externalization, extension, and output of human. Media is all about human culture" [1] use this perspective to look at architecture propagation, architecture also extends the human behavior, psychology, and even power, architecture have more characteristics of "Non-mobile" solid state media. People often use building as a landmark or location indicator, building entities do have information confirmation, information reception and information shaping. In fact, "a building from the date of construction in addition to space, function, form, construction technology, the usual architectural properties, it also plays the role of the media, with the communication attributes."'[2] Just like the value of life in architecture also allows the construction play a narrative "oral myth, regional folk customs, historical memory" of the "active medium" function. The wide area of its spread involves the entire architectural life cycle of social history and cultural ethics, and access to proliferation, continuation, destruction and nurture. "From a comparative perspective, a group of ancient civilizations that were first conceived on the way of human cultural evolution were largely destroyed by violent attacks of raging and destruction, and human creativity and self - destructive power were almost equal." [3] In the destruction and renaissance of culture, the space-time span of architecture makes it become the base of culture. Building as a medium dutifully it 
provides a basis for recording the humanities of the previous generation, architectural patterns complement the unspeakable text of civilization gene that cannot explain, and even carries a symbolic translation of the visual form of social ethics. In general, the information recorded in the text when reading with the environment, narrative, understanding and other reasons will have a bias, a complex construction technology language that cannot replace the object. Mr. Sicheng Liang for building the wooden pagodas in Ying county Liao dynasty had drawn a large number of illustrations, these illustrations are simply text and how to explain it clearly. Especially, when people face the surviving wooden tower, the visual shock and direct understanding of the structure is always beyond the illustrations and text description. Wood structure used in the process, in a sense with the builder's thinking in the real state to maintain a link, thus, pushing the intrinsic social ethics and collective consciousness. In this perspective, substance narrative of architecture and image text also has the function of media communication.

\section{Architecture through the Dissemination of Social Ethics}

The unique form of Chinese traditional architecture is symbolic, which is consistent with the social ethical expression. That is to say, the Chinese architectural narrative media is unique in the use of symbolic association to influence the subconscious ethics. McLuhan, in his writings, discussed the media function of housing construction, saying that "buildings and human beings, like other inventions in the process of evolution, are a communication medium that can influence and reshape the living patterns of human groups".[4] Chinese traditional architecture has the characteristics of "synchronic space frame", its form always intuitively expresses the balance between implicit politics, nature and belief, moreover, embodies the standard of social centralized mode and hierarchical social order. Traditional Chinese architectural symbolic system presents a three-stage composition, as the geometric epitome of natural things, extending the body's memory. The bottom of the building with a square platform load (Book of Rites - Record of Music) dignified and upright without partial evil, also etiquette and ceremonial modeling requirements, highlighting the instinct for the body's sense of stability. "High base dignified" platform also echoed "top cover indulge" of the roof curve, In order to form a diagonal Yu-yang hold cornices, the shape of the "Kao Gong Ji" the so-called " A four heavy eaves" (hip roof style). The roof side of the slope (hanging mountain and hard mountain) is like kraken roc wings of flying posture, shown in Figure 1, metaphor of the physical instinct of the free space desire. In Cao Wei era He Yan (Jing Fu Temple Fu) described the "flying razor wings is Fan-Yu (The tiles of the roofroll up on the eaves) or Gao-Xiang (lift off)", derived the mythic symbol of "The Promise of Heaven". Cornices in accordance with the occupant's identity power have different forms of mimicry eaves, The Forbidden City and Temple of Emperor used double eaves hip roof palace style, the curve of atmospheric stretching expresses the holiness of the emperor, this is the roof form between the signifier to highlight the "Kraken roc" form symbol of the superiority and humble etiquette. Confucius said: the power of the country is in the "weapon and sacrifice", the state of "Ge(dagger axe)" and "Yu(Jade)", is clearly the source of China's design to create a culture, the implementation of the power cannot be separated from the space of the ' under the overlying cover'. 'Jade' word structure is central axial symmetry; this is the great tradition of civilization clan commune 'fair, average' primitive thought, transformation in China is to create the straight and balanced layout construction 
principle. 'Ge' word structure in the 'restrain strokes' like the traditional Chinese architecture 'wing-style' big roof, the beautiful wingspan in accordance with the longitudinal axis of the ends of the tilt into the 'Fan-Yu curve', but also like kraken roc's wingspan. [5] General residential roof "cover" is only "shelter" function, while hip roof and hip-and-gable roof however, borrow the ethical boundary of "Flying". Obviously, these roofs represent the ethical meaning of the people, a "solid-state media" that aggregates the image of state power, publicizing social order and universal values. "Kraken roc" is the recorded myth image in ZhuangZi (Gateaway); many scholars have carried on the rational research of "Creation and Sun Trajectory", ShuXian Ye believe that the evolution of Kraken roc is related with the orbit of sun, He deduced that the sun bird was swallowed by the sea scales and was spit out the next day, and thus be the sun creation myth.[6] Guangming Wu think Kraken roc is "to imitate the prevailing universe formation theory of the doggerel". [7] Renfei Zhu consider that "birds and aquatic animals transformed into a mutual deformation of the chain of life, in one article of (Gateaway) eel evolves into kraken roc allegory is generated in the conception of the material produced under theinterpromoting relation in five elements. [8] Zhongtai in (Discussion of ZhuangZi) easily explain the evolution of kraken roc, is a symbol of "Zhaoming was born in somewhere. The word "Kun (kraken)" also for the word "Hun (mixed)", Lao Zi said there are things mixed into, congenital births."ZhuangZi expression represents a body's desire for freedom, architecture is always embodying certain "simulation and analogical" cognition of the body, as Fry said: "Myth is a series of actions imitating, Or at the expected limit of desire."[9] If ZhuangZi's speech represents the creation message of the universe, the sacred concept will be used in the architectural form most directly affected by the body, and the "ethical" extension of the Confucian ideology will become the dissemination of "wisdom" and "benevolence" of the media narrative. "The world gives a myth to a historical fact that it can even be produced or used by humans in a way that retraces for a while; and the myth returns the natural image of reality."[10] Here the traditional architectural roof cornices kraken roc myth image expressed the historical facts by Roland. Barthes, for thousands of years, people have used their natural forms to describe the myth of Zhuang Zhou, when people construct and look up, the intuitive nature images are combined with historical facts in the same semantics.

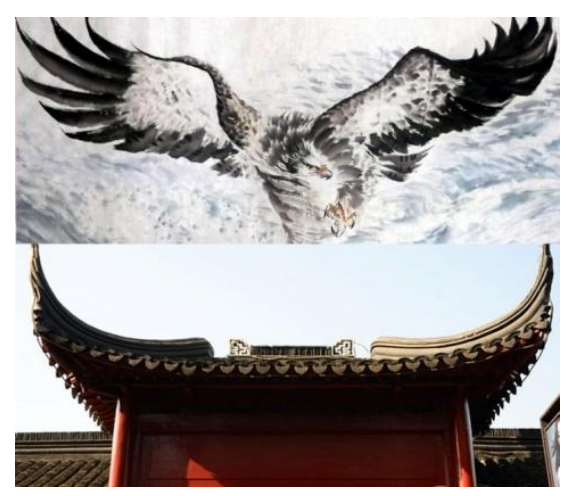

Figure1. Architecture wingspan of flying posture

The traditional Chinese roof structure is dense and complex, the "Close-packed" roof tiles and the "accumulation" of the brackets, jointly follow the order of the static, and the floating and flexible roof constitute a balanced rhythm, on the ridge, a row of "immortal" 
lined up and the Owls kisses are facing each other, the order and romance are presented perfectly, revealing the morphological ethics in the analogy between power and law. Therefore, when Wang Shu and Wei Yan in China Academy of Art Xiangshan campus create a "Shan Lin" actually has chosen to "arrange tiles" extension of natural hillside, as shown in Figure 2. Wang Shu even explore the "Qingming River" of the "Row arch" structure, toramming the old rubble composition of the wall as "Wa Shan", the intention is to pass on the traditional skills of Song Dynasty that are simple and unadorned. Xiang Shan campus building has many stretched roof, high vertical walls of plain soil and brick pavement, divergent Jiangnan building unique subtle, It is a simple and concise structure of Bauhaus-style, which is based on the architectural form of Chinese and Western art narrative of the relaxation tactics, to spread the ideal space of living space in architectural form, and to cultivate the social justice system ethics.

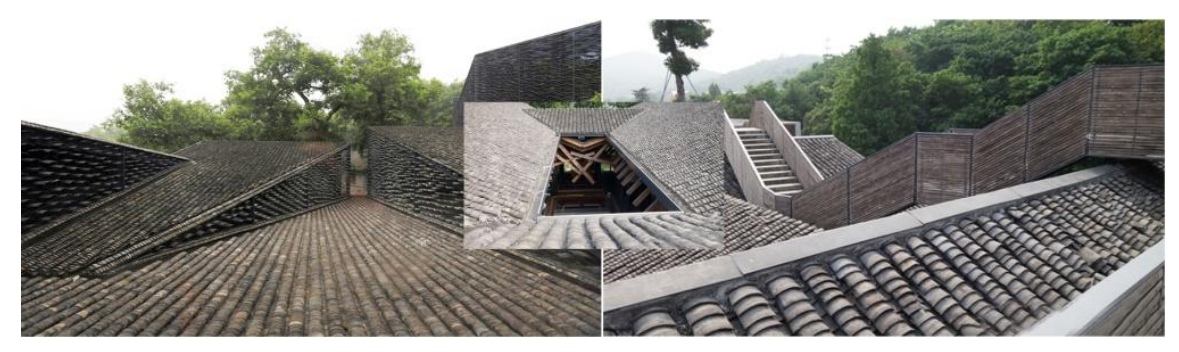

Figure2. Wa Shan arrangement

\section{Architectural Space Limitation and the Complementarily and Unification of Social Ethics}

Classical Chinese building facade and layout, is from the site selection ethical search, the so-called FengShui geomancy. (Classic of Changes - Copulative Book) The saying goes: "Ancient King of the world Bao Xi Shi (Fu Xi), look up to observe the sky, bend over to determining the terrain, and observe the patterns of birds and animals that are favorable to the earth, as a result to create the eight trigrams, in order to reach the deity of the gods, analogy to the situation of all things." Eastern Han XuShen said: "Geomancy is the authentic heaven." Indicate that geomancy of science and reason lies in the way of heaven and earth, the Chinese people pay attention to the world of all things animism. (Classic of Changes - Copulative Book): "The Yi was made on a principle of accordance with heaven and earth, and shows us therefore, without rent or confusion, the course (of things) in heaven and earth. (The sage), in accordance with (the Yi), looking up, contemplates the brilliant phenomena of the heavens, and, looking down, examines the definite arrangements of the earth; - thus he knows the causes of darkness (or, what is obscure) and light (or, what is bright)." The traditional Chinese way of understanding heaven and earth is the same with the modern geophysical science, the myth of (Shan Hai Jing - HaiNei Jing) records:"When the flood overflow from heaven, at that time, Gun went to steal God's treasure - The Living Soil (one kind of soil that can grow endlessly) to fill the flood without permission of the God. Furthermore, God became angry and calledVulcan to kill Gun in the hills of the Yushan country. But from the stomach of the Gun who was killed, he gave birth to his son Yu. The God had ordered $\mathrm{Yu}$ to expand the soil, put down the flooding in nine provinces.'Dayu won the public morality due to flood control, manage the water as rule the nine provinces, the stability of nine provinces are 
the founding of the country, the subsistence of water will also subside the stability of farming. The act of $\mathrm{Da} Y \mathrm{Y}$ have formed the morality and power of Xia dynasty, although the legend is virtually a social ethics, which is the Confucian "knowledge of things to know", the idea can be the basic implement in later generations, more in line with the characteristics of agricultural society that rooted in the land.

From the rigorous point of view of the Xia Dynasty text is currently waiting for new discoveries, the real situation of its propagation even more to be studied. In 1959, the famous Chinese archaeologist, Mr. XuXusheng, led his team to inspect the Xia Ruins and found Erlitou ruins in Yanshi County, Henan Province. (Zuozhuan - Zhuanggong twentyeight years) records, "in Fan citythere are ancestral temple of the Lord", Corresponding to Erlitou site "temple" location layout is undoubtedly the Xiadu site. The ruins of large palaces, tombs and a large number of bronze unearthed, is revealed the existence of the physical evidence of the Xia Dynasty. Xia Dynasty palace built in three layers above the pebble base, presumably large with eight rooms, in the three deep room, with wooden pillar, straw for the skin, four slope of the eaves of the hip roof style large-scale wooden building, the courtyard is equipped with pottery and stone slabs of underground drainage facilities. The building structure is around $1600 \mathrm{BC}$, and the structure of the narrative and later architectural ethical expression is basically the same. Base on three-tier, the central axis discrete layout, four heavy eaves, and eaves column three symmetrical combination of the holy verandah hall. According to the archaeological expert Xu Hong to provide Erlitou site excavation plan, we can see the site of the main hall of the circle of columns are all triangular arrangement of the "triangle column group", each group consists of three columns, followed by a eaves column, flush with the wall, In front of two eaves columns, three pillars arranged in a triangle. In one passage of $\mathrm{Mr}$. Fu Xi Nian's (A Preliminary Study on the Construction Site of Chenxi Zhou in Fufeng) book written: "F5 platform surrounded by a circle of prop up eaves pillars, about $15 \mathrm{~cm}$ in diameter, so there should be a circle under the eaves.From the drainage to the platform side distance to see, the underneath of the eaves about 80-90 cm",[11] This shows that the construction level of the Zhou Dynasty in China has shown a three-stage composition, the application of the middle section of the eaves columns, commonly refers to the eaves column set in the hall, room, veranda of the platform side and stairs, the spacing is dense than the corridor pillars, column diameter also smaller than the pillars, the function is to hold out more eaves head. From the Xia and Shang dynasties of the architectural ruins can be seen "the spacing is dense than the corridor pillars", mostly the "triangle" forms a set of columns. In the Han Dynasty, the "triangular column group" has been transformed into a rich Chinese stylethe "One man hold the sky" and"The conqueror lift up the tripod" by the deduction of technology and mechanics, as shown in Figure 3, which provides the structural foundation for later development of brackets arch.Hongling Qin once wrote, "The typical characteristics of ancient Chinese architectural culture, which began in the Xia, Shang and Zhou dynasties, did not undergo substantial changes in the dynasties of the following two thousand years, and they were the basis for any ancient architectural culture in the world, this is our keys to understanding and grasps the ancient Chinese architectural ethics."[12] Erlitou palace ruins to square the layout of the prototype, the square represents a special construction meaning, in the Shang Dynasty palace ruins floor plan, we can only see the four and eight even number room... the adoption of four and eight even number might be related to "Four-side system" of "Four rooms eight 
chambers" other related records, this "symbolism" composition means that the emperor as a leader is to be "in all directions".[13] The main building and hall entrance arch building are in center, from the square leads to absolute power and the inferiority metaphor. The hall in the open three-tier cobblestone pedestal on the set of three-cornered eaves pillars support the herringbone lift frame,to create a "courtyard" to other boundaries, corresponding to the "Greeting and bowed to each other"etiquette of the order, construction of the structure as a "ritual benevolence" implementation of the echo scene. From the perspective of ethical transmission, the classical architectural form is the "visual form connection" of the Confucian man's thought which introduces the spirit of the entity's place. "Gentle and honest Confucian ethics of poetry, is always the core values of Chinese culture. How to make male personality be neutral transformation, that is, the direction of transformation of non-masculine remodeling, how to remove the offensive potential of human nature, Confucianism, Taoism, Buddhism, the great confluence of the three religions, but also Chinese culture, the world's ideological dedication."'[14] It is difficult to reproduce the architectural structure of the great traditions, but the ruins of the palace or because of the scale and exquisite materials, still provide a research value for the people today. Chinese classical architecture provides a symbol of perception for the moral character of "gentle and honest", "kind or tender", "Everyone can be Yao Shun", which makes Chinese civilization dwelling poetic. Traditional architectural form "into a reflection of the 'moral inspiration' thinking can be any society and any era of 'design gist', it is shielding the increasingly toxic modern process of ecological bad, extravagant corruption, conscience hypocrisy and other social problems constructive, rational solution to its 'systematic universal' interpretation into the contemporary design of the daily life can become a cultural heritage of China runway."'[15]

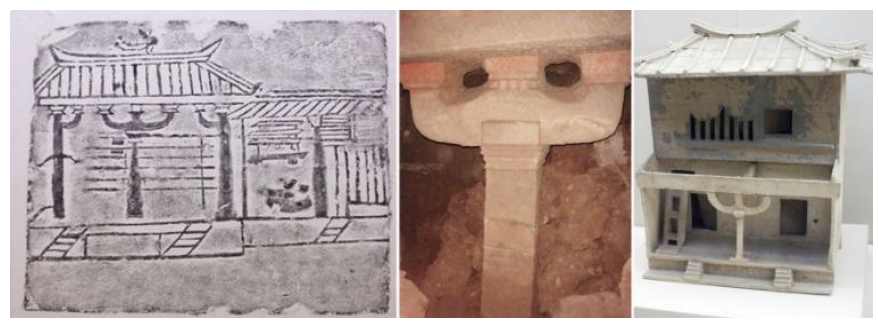

Figure3. Looks like a man lifting

\section{Symbolic Component as Ethical Propagation of Visual Media}

The ethical propagation system of traditional China architecture still lies in the application of "conscience" in the whole society. In the principle of ethic replacement of "dos and don'ts", no evil intention, plot a murder and "have something to do" doing good deeds, accumulating virtue, showing manners, temples and civil architecture found the appropriate form to symbolize language, each construction has completed the ethical system to provide a kind of media expression of Chinese people aspire "common justice". The layout of ancient Chinese building is always based on a major longitudinal axis, and the main building is arranged on the main axis, the secondary buildings are located on both sides of the main building, east and west both are standing opposite each other, build up a square or rectangular courtyard. The layout of this courtyard is not only meet needs of life such as safety, expose to the sun and prevent from the cold weather, but also meets 
China's ancient society patriarchal and feudal code of ethic system."[16] Axis becomes spatial visual form through ethics, which is the ethical manifestation of Chinese traditional architecture. The vertical axis represents national group sacred symbol of faith through time and space by the door, uses door's size and open-close to make up sympathetic coincidence, and while the horizontal axis expands corridor ceremony between the columns, the symbolic image of architecture has been given to the meaning of ethical order, between the vertical and horizontal create timing and power. The central axis generated by the door of the second order in the temple is the power, in religious architecture is ritual, for common people is to proceed or step back freely. Traditional Chinese Fengshui believes that south axis has the meaning of powerful forces of nature, only the king can control, and poor people should avoid south wind in the upper space, therefore the absolute straight axis is always set "circuitous structure". Therefore, the layout of private courtyard since guard screen is start operating axis, through entrance to screen wall or hall "openly" avoidance setting, whereas the guard screen implicates people should check their appearance and attires, it is the simplest of common people daily ethical behavior "Orderly filial piety".

China Architectural style of the door, function and symbol are the codes of ethics and polysemy, enlightenment, politics, consanguinity, gender can be decoded according to different scenarios. In the "Cheng-Zhu's ancestral home" in Anhui, keep a large number of complete "Chastity arch", this unique "three - dimensional ceremony", from a message which is a door of symbol of special significance, etiquette, commemorate, geographical location. Expressed in the Patriarchal Jurisprudence of the strict laws of the ancient Huizhou, archway outside extended out distortion psychology of patriarchal business, by architectural form highlighting the respected chastity lady style, ostensible purpose is to spread "Award of Honor and Moral Model" But in the actual evolution of connivance of extreme gender-distorted cognition, become the "ritual" of the media rather than ethical and orderly media. As Wang Xiaochong said: "Compared to the national level of praise and clan level advocacy, chastity arch in the space is to release the deterrence and call to achieve a more effective publicity, through this space building to pass out, the silent, effective social psychological hint, under the influence of psychological suggestion, more and more Huizhou women embarked on the "Chastity'." [17] And this "chastity" at the sacrifice of the number of nature and beauty, which is a traditional building by the ethical negative representatives, the extreme meaning of the cover and distort the spread of the ethics of justice.

In addition to the door, the wall also has beyond the actual function of the media implicit, the Forbidden City in the slow long wall put the sky to repair into a narrow mode, while the psychological mood is also in the long and narrow deposition of their identity to read.(MoZi - CiGuo) contains: "When the ancient people do not know how to make the palace, live close to the mountain, live in the cave, underground humid, hurt the people, so the king began to create palace. The principal to make a palace is the height of foundation should avoid the wet, four sides enough to resist the cold wind, the roof is sufficient to prevent frost and rain, the height of the wall is sufficient to separate the inside and outside, to show etiquette between men and women, that is the point." In the book of CiGuo, Mozi stated very clear that the building should shelter from wind and rain, avoid cold, and also set the walls to show etiquette between men and women. This wall is beyond the reality and becomes the class media, symbolizing the "cut-off" of sex-evading, 
which carries the universal significance of the society, and gradually forms the innercourt and outer-family homes in Chinese traditional architectural world, family relationship and gender ethics environment. China has a strict theory of enlightenment, its function class law but more conscious and active than the law. In the book (Wang Zhi)XunZi pointed that: "Pay attention to ritual music, correct behavior, promote education, and improve customs". [18] The traditional China could be educated was not contemporary social significance of "nine-year system", many uneducated people, start from the cognitive, the building provides a rich semantic, architectural visual components (brick gatehouse, portrait brick, eaves tile, decorated bracket) become the mundane "text" for women and children, Chen Lai said: "The ancient rituals in the artifacts, cars, the complexity of the arrangements in the social function of the hierarchy is to clarify the boundaries of hierarchical system, the level of the color gain system, strengthen the hierarchy of distinction." [19] Since the Han Dynasty "Domination of Confucianism" Confucianism pay attention to the ideological and material synchronic nature of human ethics and moral guidance, around the pattern of mortal life trying to the same with the Confucian doctrine, and the symbolic communication language of visual form, which is built outside the "Four Books, Five Classics and Six Arts", "Confucianism advocate respect and order, different from top to bottom, with emphasis on building to reflect the superiority and humility order, where the building of the bay, shape, color ridge decoration, has strict requirements, shall not violate the transgression." [20] However, since there was statute of limitations, people will not show "humanity evil" and let their desire beyond reality. Therefore, the construction of Confucian texts, material narrative ethics and social structure, "from top to down" is the poetry and etiquette, country temple order was fit in the specification, "From down to top" hundred workers comply with social morality, the overall community has the basic ethics. However, the richness of contemporary social architecture, its ethical value is worthy of reflection, to be awakened to explore the traditional architectural form of ethical manifestations. Should be seen in the "hierarchy" in order to reflect the value of the social order, the degree of constraint may be able to put an end to the expansion of many super personal ideas, moreover it is to eliminate the White House in China's "growth", Tiananmen tower "resurrection" in the town office building. The media have reported a number of "White House" appearance of the Chinese local conquest, courts, EPA and even wineries, as many as a dozen, it was impelled to speak that it was an amazing phenomenon, why the local government abandoned the traditional Chinese temple dignified architectural form and invariably choose the White House architectural form as the representative? Was it the beauty of the psychological, or the servility of the nation? The writer believes that the design must be playing a guiding role, reshape the soul of traditional construction in "practice".

\section{The Practicing of the Traditional Architectural Language and Constructing Social Harmony}

Traditional Chinese architecture in addition to its technology, structure, and layout, but also carrying a special aesthetic decorative coding. China is a very heavy decorative language of the country, because the decoration is to express respect for all things, return to nature is the core of the building embodied "ethical" dependency. "In the long history of human architecture, architecture to meet people's physical and psychological needs, is a tool for human services and carriers, this concept is always the architectural design can 
not deviate from the 'origin', is never diminished architectural ethical consciousness core.'[21] Those elegant brackets under the roof, are lined up undertake the bearer, but also as a tree-like growth, as shown in Figure 4. Intuition of ecological links cannot even make the Chinese people entrust to the care of construction of the "high hopes", therefore, in a blink of an eye there are still "Ornate sparrow", even like "Angel Wings" and "Holding Hand". Those Road endless "mythology hero, totem legend, ethical auspicious, gifted scholar, Fu Lu Shou Xi (Chinese deities)" are in the Ang (Oblique components in the bucket), bucket, column, and architrave roaming. And China's special combination of cultural couplets is become a social encoding expression, to build beyond the temporal and spatial semantic monasteries, to provide the "courtesy" textbooks for the education of children and grandchildren in ethnic courtyards. These forms capable of "reading" the propagation of the past two thousand years to correct human behavior, dissemination of ethical values, as in Cassirer's "symbolic activity": "In history, people live in a world of symbols they create, people create symbols, and in turn it shape people. The symbol becomes the mediator between human and "world", which is the form symbol. People in the construction site of the "line", their consciousness and the unconscious (including physical instinct) have become symbols of the main activities, that is, in the time of the "symbolic activity." [22] The symbolic activities that penetrate the traditional Chinese architecture are "ethics", the ethical symbols that teach people to be kind to all things and ceremonial shame. Traditional Chinese architecture can be described as ubiquitous ethics, there is the "king axis" royal palace and religious architecture (Zhao Guangchao language), which embodies the "institutionalization" of the ancestral temple building, but the main body is "harmony and beauty", The Chinese ancestors of the wisdom and symbolic capacity of creation and romantic imagination, simple creation of nature, it is the contemporary social spirit that must be considered and inherited.

Promote urban development and prosperity of the country's power, must not destroy the culture of self-violence patterns, other blitz fashion-oriented civilization, but it must be "from the inside" that transmit from the prototype culture. When people talk about Western fashion and technology, may be forgotten and ignore the most meaningful of cultural prototype. When people make the homogenization of rural and urban time, it is lost with the folk culture of ancestral area culture. Civilization of the heritage and the gene has always been a historical imprint, a direct way to smear as destroyed. Once the ancient Egypt, ancient Babylon, the ancient Maya, the ancient Indian civilization are wiped out in no recovery, it is human pain and ignorance. As Mr. Qi Kang said: "The way people doing things is a historical trajectory, it is the most important mark in human history, people develop rules to protect, to commemorate, and cherish it, in this way it plays the role of education."[23] Then the contemporary "Knowledgeable person" should have the responsibility to look around, consciously bear the cultural understanding and reproduction, some representatives of professional authority, the government power should consciously carry "conscience" to design and planning the treatment of social dissonance in the era of new media screen that can effectively communicate with international cultural communication on behalf of the Chinese architectural style of civilization. 


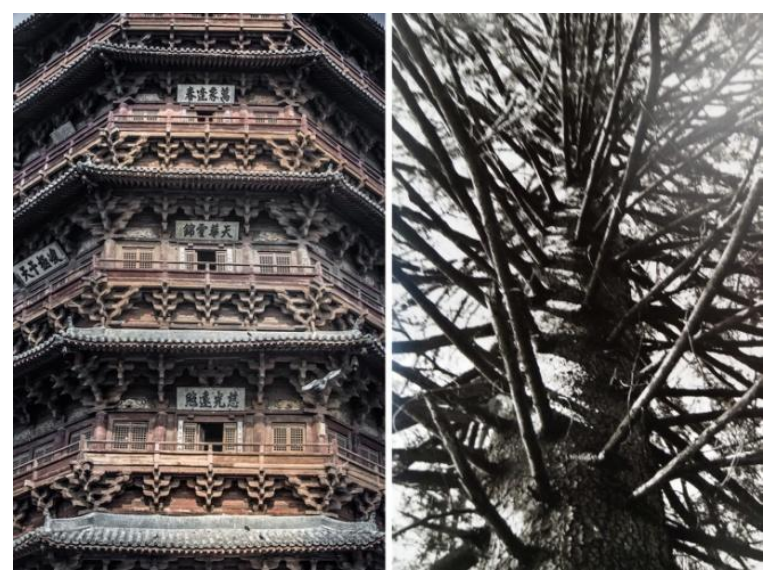

Figure4. Cascading order and large tree prototype

\section{Acknowledgement}

University of Shanghai for Science and Technology Humanities and Social Sciences project (16HJSK- ZD01)

University of Shanghai for Science and Technology "Excellent Undergraduate" Series of research projects funding

\section{References}

[1] [CND] EricMcLuhan [CND] Frank Zingrone, He Daokuan, Essential McLuhan [M].Nanjing: Nanjing University Press,2000.10,p8.

[2] Li Xiaofeng. The Significance of Architecture as Media[J]. Time+Architecture. 2014.6. p62.

[3] Ye Shuxian, The Abdication of Yao and Shun: the Historical Construction of Confucian Political Myth [J].National Arts, 2016(2).p40.

[4] MARSHALLMCLUHAN. Understanding Media: The Extensions of Man[M]. New York: New American Library, Inc. 1964. p12.

[5] Xiong Chengxia, Traditional narrative ethics of activation and new research [J]. ZHONGHUA WENHUA LUNTAN, 2016(6).p108.

[6] Ye Shuxian, The Philosophy of mythology of China. [M]. Xian: SHAANXI PEOPLE'S PUBLISHING HOUSE, 2005(5) p63.

[7] Zhu Renfei, Decoding and Analysis of Zhuangzi's Myth [M].Chang chun: NORTHEST NORMAL UNIVERSITY PRESS, 1999.4

[8] ZhongTai, ZhuangZi made micro [M].Shanghai: SHANGHAI RENMIN CHUBANSHE, 1988.1

[9] [CND] Northrop Frye, Chenhui. Yuan xianjun. Wuwei, The Critic of the Judgement [M]. Tianjin: Baihua Literature and Art Publishing House 
[10]Roland Barthes, $\mathrm{Xu}$ qiangqiang, $\mathrm{Xu}$ yiling, Mythologies Roland Barthes [M].Shanghai: SHANGHAI RENMIN CHUBANSHE, 1999.3, p202.

[11]Fu Xinian, A Preliminary Study on the Construction Site of Chenxi Zhou in Fufeng of[J].Cultural relics1981(3).p39.

[12] Qin Hongling, The Institution of Palace and the Governance of Palace: An Analysis of Institutionalization of Ancient Chinese Architecture [J].Studies Ethics.2014 (5).p32.

[13] Li Yunhe, Chinese Artisan - Analysis of the Design Principles of Chinese Classical Architecture [M].Tianjin: TIANJIN UNIVERSITY PRESS, 2005(5).p138.

[14] Ye Shuxian, The Abdication of Yao and Shun: the Historical Construction of Confucian Political Myth[J].National Arts,2016(2).p46.

[15]Xiong Chengxia, Value of Chinese Traditional Artifact Design Based on the "Looking Cultural DNA" Vision [J].Design History and Traditional Creation,2015(12).p72.

[16]Liang Bianfeng, Exploration into the Ethics of Ancient Chinese Architecture[J].Studies in Philosophy of Science and Technology,2013 (2)p99.

[17] Wang Xiaocong, Huizhou chastity arch and chastity women[J].Review of Social Sciences, 2007(3):34-39.

[18] Wang Xianqian, Doctrine and explanation of XUNZI[M].Beijing: ZHONGHUA BOOK CO.1988. P170.

[19] Chenlai, Ancient Religion and Ethics - the Root of Confucianism [M]. Beijing: SDX Joint Publishing Company2009. P299.

[20] Wang Qijun, Chinese ancient architectural language [M].Beijing:2007: 187.

[21]Qin Hongling, On the Basic Principles of Architectural [J].Studies Ethics.2015 (6).p94.

[22] Yin Guojun, Symbol Empire [M].Chongqin: Chongqing Publishing House 2008(3).p70.

[23]Qikang, Architectural Morphology Architectural Heritage [J].Architecture \& Culture, 2015(1) p34. 